\title{
KAJIAN TERHADAP BENTONIT DI KABUPATEN TASIKMALAYA DAN KEMUNGKINANNYA DIJADIKAN BAHAN PEMBERSIH MINYAK SAWIT (CPO)
}

\author{
Oleh : \\ Ganjar Labaik \\ Kelompok Kerja Mineral, Pusat Sumber Daya Geologi
}

\section{SARI}

Perkembangan industri minyak goreng sawit pada dasawarsa terakhir mengalami peningkatan sejalan dengan beralihnya pola konsumsi masyarakat dari minyak goreng kelapa ke minyak goreng kelapa sawit. Konsumsi per kapita minyak goreng Indonesia mencapai $16,5 \mathrm{~kg}$ per tahun dimana konsumsi perkapita khusus untuk minyak goreng sawit sebesar $12,7 \mathrm{~kg}$ per tahun. Berdasarkan perkembangan berbagai variable terkait seperti peningkatan konsumsi minyak goreng untuk keperluan rumah tangga maupun industri diperkirakan total konsumsi minyak goreng dalam negeri tahun 2005 mencapai 6 juta ton dimana $83.3 \%$ terdiri dari minyak goreng sawit.

Sebagai bahan untuk penjernihan minyak kelapa sawit diperlukan bentonit jenis kalsium bentonit (CaBentonit) yang banyak tersedia didalam negeri. Permasalahannya apakah bentonit lokal ini bisa memenuhi speifikasinya untuk itu ?, dan bagaimana bentonit lokal ini harus dapat di daya gunakan ciimasa mendatang agar kebutuhan bentonit ini tidak terlalu tergantung pada bentonit impor, sehingga pada gilirannya bisa menekan seminimal mungkin bentonit impor.

Potensi bentonit di Kabupaten Tasikmalaya, Provinsi Jawa Barat mempunyai sumberdaya sebesar 19.812.600 ton diharapkan dapat memberikan sumbangan dalam rangka mengurangi impor bentonit.

\section{PENDAHULUAN}

Perkembangan industri minyak goreng sawit pada dasawarsa terakhir mengalami peningkatan sejalan dengan beralihnya pola konsumsi masyarakat dari minyak goreng kelapa ke minyak goreng kelapa sawit. Konsumsi per kapita minyak goreng Indonesia mencapai $16,5 \mathrm{~kg}$ per tahun dimana konsumsi perkapita khusus untuk minyak goreng sawit sebesar $12,7 \mathrm{~kg}$ per tahun. Berdasarkan perkembangan berbagai variable terkait seperti peningkatan konsumsi minyak goreng untuk keperluan rumah tangga maupun industri diperkirakan total konsumsi minyak goreng dalam negeri pada tahun 2005 mencapai 6 juta ton dimana $83.3 \%$ terdiri dari minyak goreng sawit (tabel 1).

Namun demikian dari 79 pabrik yang ada di Indonesia, belum semuanya berproduksi secara maksimal, baru sekitar $31 \%$. Produksi terbesar minyak kelapa sawit berada di Pulau Jawa dengan kontribusi terhadap produksi nasional sebesar 51.4\%. Disusul dengan Sumatera sebesar $47.5 \%$ dan Kalimantan Barat $1.1 \%$. Selain itu permasalahan yang lain adalah belum terintegrasinya produksi dalam satu sistem industri dari hulu ke hilir.

Sebagai bahan untuk penjernihan minyak kelapa sawit diperlukan bentonit jenis kalsium bentonit ( $\mathrm{Ca}$ Bentonit) yang banyak tersedia didalam negeri. Permasalahannya apakah bentonit lokal ini bisa memenuhi spesifikasi untuk itu ?, dan bagaimana bentonit lokal ini harus dapat di daya gunakan dimasa mendatang agar kebutuhan bentonit ini tidak terlalu tergantung pada bentonit impor, sehingga pada gilirannya dimasa mendatang kita tidak lagi mengimpornya dan tidak mustahil mempunya daya kompetitif dipasaran internasional.

Jumlah bentonit yang diperlukan sebagai bahan penjernih minyak akan sama jumlahnya dengan 2,5\% - $4.0 \%$ dari jumlah minyak sawit (CPO). Maka untuk pemakaian 6 juta ton minyak sawit (CPO) pada tahun 2005 ini akan menggunakan bentonit sebanyak 150.000 ton -240.000 ton.

Sampai saat ini Indonesia masih mengimpor sebagian kebutuhan bentonit dalam negeri untuk 
memenuhi berbagai keperluan bahan industri terutama jenis bentonit untuk penjernih minyak kelapa, bagi keperluan rumah tangga dari berbagai negara maju seperti Jepang, Amerika Serikat dan Inggris.

Dari sekian banyak komoditi bentonit untuk penjernih minyak yang tersebar di seluruh Indonesia, maka bentonit dari daerah Kabupaten Tasikmalaya, Provinsi Jawa Barat ini dapat memberikan sumbangan dalam rangka mengurangi import bentonit. Karena berdasarkan hasil penyelidikan ternyata spesifikasi bentonit ditempat ini telah memenuhi standar baku yang ditetapkan dan juga memiliki sumberdaya bentonit tereka yang cukup banyak yaitu sebesar 19.812.600 ton. (Martua Raja P., dkk.., 2002.).

\section{GEOLOGI ENDAPAN BENTONIT}

\subsection{Tinjauan Umum}

Bentonit adalah suatu istilah nama dalam dunia perdagangan yang sejenis lempung plastis yang mempunyai kandungan mineral monmorilonit lebih dari $85 \%$ dengan rumus kimianya $\mathrm{Al}_{2} \mathrm{O}_{3} \cdot 4 \mathrm{SiO}_{2} \times \mathrm{H}_{2} \mathrm{O}$.

Nama ini diusulkan pertama kali oleh Knight (1898) untuk nama sejenis lempung koloid yang ditemukan pada formasi Benton "Rock Creek" Wyoming Amerika Serikat.

Penamaan istilah bentonit diusulkan sebagai pengganti dari istilah nama lain sebelumnya yaitu "Soapy Clay" atau "Taylorit" yang dipopulerkan oleh Taylorite (1888). Sedangkan nama monmorilonit itu sendiri berasal dari Perancis pada tahun 1847 untuk penamaan sejenis lempung yang terdapat di Monmorilon Prancis yang dipublikasikan pada tahun 1853 - 1856. Grim (1968) mengelompokkan monmorilonit ini kedalam Smektit Group sub kelompok smektit di-oktahedral (heptaphyllitic) bersama dengan beidelit dan nontronit. Sedangkan sub kelompok lainnya adalah smektit tri-oktahedral (cetaphyllitic) yang terdiri dari mineral hektorit dan saponit.

Secara megaskopis bentonit dapat diamati secara langsung dengan ciri khas yaitu : mempunyai kilap

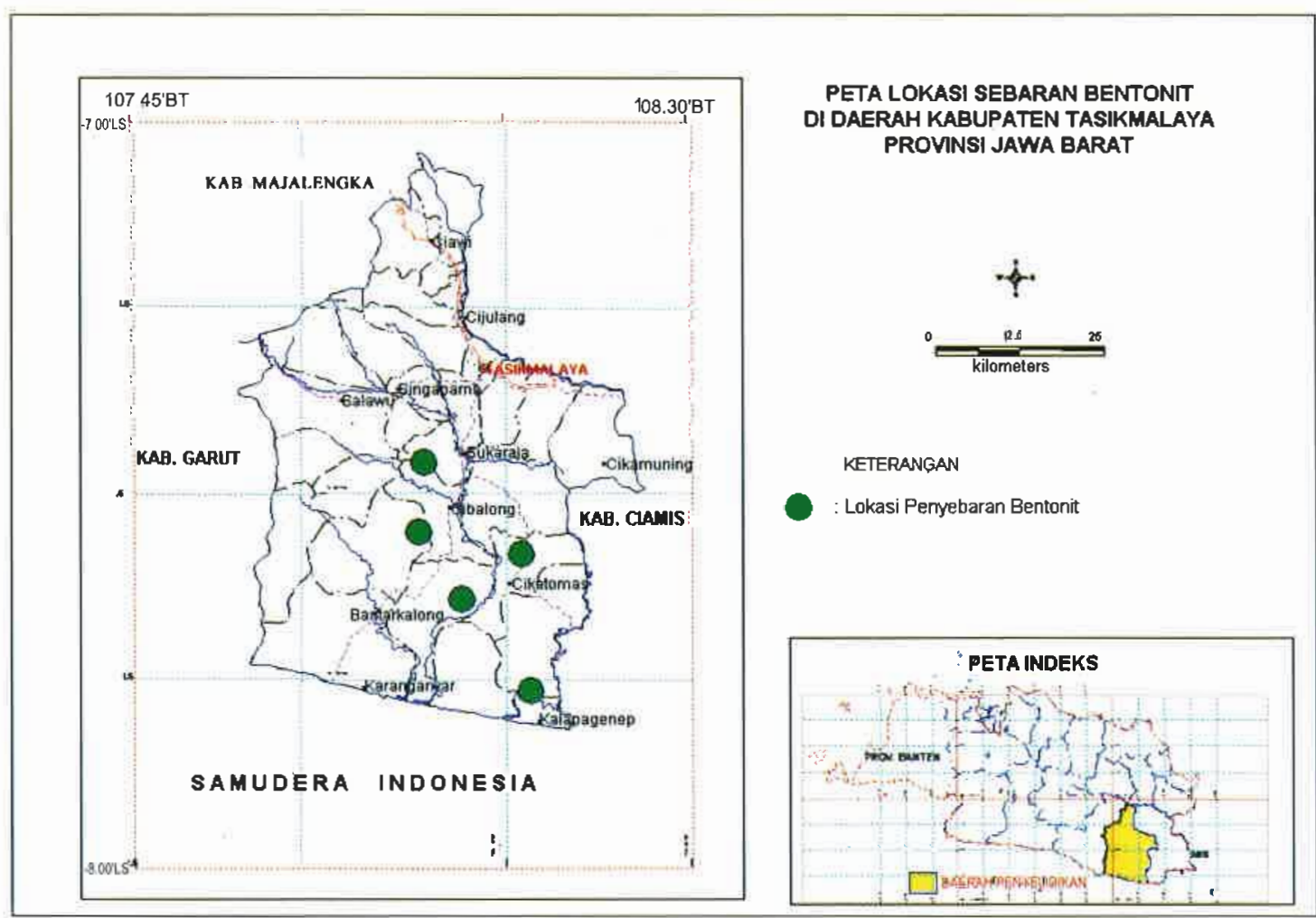

Gambar 1. Peta Lokasi Sebaran Bentonit Di Kabupaten Tasikmalaya 
lilin, Junak, , berwarna abu-abu kecoklatan sampai kehijauan.

\subsection{Genesa Bentonit}

Mula terjadinya Bentonit secara umum dapat dikelompokkan menjadi empat jenis endapan yaitu hasil endapan dari proses pelapukan, hydrothermal, tdevitrifikasi dan endapan sedimen.

\subsubsection{Proses Pelapukan}

Bentonit ini terbentuk akibat proses pelapukan dari mineral-mineral penyusun batuan yang dipengaruhi oleh iklim, jenis batuan, relief muka bumi, tumbuh-tumbuhan yang berada diatas batuan tersebut.

Faktor utama yang menyebabkan terbentuknya jenis mineral lempung dalam proses ini adalah komposisi mineral batuan, komposisi kimia dan daya larut air tanah.

Pembentukan mineral lempung oleh pelapukan adalah akibat reaksi ion-ion hidrogen yang terdapat dalam air tanah dengan mineral-mineral silikat. $\mathrm{H}^{+}$ umumnya berasal dari asam karbonat yang terbentuk sebagai akibat pembusukkan oleh bakteri terhadap zat organik dalam tanah.

Menurut Wollast (1967), pada proses pelapukan bila laju aliran air lebih cepat dibanding dengan pelarutan yang terjadi, biasanya didaerah curam maka akan terbentuk gibsit $\left[\mathrm{Al}(\mathrm{OH})_{3}\right]$ dari felspar. Dan jika laju aliran semakin rendah biasanya didaerah landai, maka dari felspar tesebut akan terbentuk kaolinit [ $\left.\mathrm{Al}_{2} \mathrm{SiO}_{2} \mathrm{O}_{5}(\mathrm{OH})_{4}\right]$. Sedangkan bila laju aliran terhenti biasanya didalam cekungan, suatu reaksi yang lambat akan terjadi antara kation dengan $\mathrm{Al}(\mathrm{OH})_{3}$ dan silika membentuk monmorilonit $\left[\mathrm{Al}_{2} \mathrm{O}_{3} \cdot 4 \mathrm{SiO}_{2} 2 \mathrm{H}_{2} \mathrm{O}\right]$.

\subsubsection{Proses Hidrotermal}

Proses ini berlangsung karena adanya injeksi larutan hidrotermal yang bersifat asam merembes melalui celah-celah rekahan pada batuan yang dilaluinya, sehingga mengakibatkan terjadinya rekasi antar larutan tersebut dengan batuan itu.

Pada saat reaksi berlangsung, komposisi larutan hidrotermal tersebut menjadi berubah. Unsur-unsur alkali akan dibawa kearah luar, sehingga selama proses itu berlangsung akan terjadi daerah atau zona yang berkembang dari asam ke-basa dan pada umumnya berbentuk melingkar sepanjang rekahan dimana larutan itu menginjeksinya.
Terjadinya monmorilonit sebagai mineral penyusun utama bentonit, terjadi karena adanya ubahan dari felspar plagioklas, mineral mika dan feromagnesian. Hal ini dapat terjadi dikarenakan adanya magnesium $(\mathrm{Mg})$ dan kalium $(\mathrm{K})$ yang berasal dari mika atau felsfar. Peristiwa ini terjadi pada alterasi hidrothermal tingkat rendah.

\subsubsection{Proses Devitrifikasi}

Pada proses ini bentonit dapat terbentuk dari hasil mekanisme pengendapan debu volkanik yang kaya

akan gelas mengalami devitrifikasi (perubahan gelas volkanik menjadi mineral lempung). Setelah di endapkan pada lingkungan danau atau laut.

\subsubsection{Proses Sedimentasi}

Menurut Millot (1970), monmorilonit dapat terbentuk tidak saja dari tufa melainkan juga dari endapan sedimen dalam suasana basa (alkali) yang sangat silikaan (authigenic neoformation) atau yang biasa disebut endapan kimia.

Mineral-mineral yang terbentuk secara sedimen yang tidak berasosiasi dengan tufa adalah attapulgit, sepeolit dan monmorilonit

\subsection{Jenis Bentonit}

Didalam dunia perdagangan terdapat dua jenis bentonit, yaitu:

\subsubsection{Natrium Bentonit}

Bentonit jenis ini disebut juga bentonit tipe Wyoming, mengandung ion $\mathrm{Na}+$ relatif lebih banyak jika dibandingkan dengan ion $\left(\mathrm{Ca}^{2+}+\mathrm{Mg}^{2+}\right)$. Secara kasat mata mempunyai sifat mengembang apabila dicelupkan kedalam air hingga $8 x$ lipat dari volume semula, sehingga dalam suspensinya akan menambah kekentalan, pH suspensi berkisar 8,5 - 9,8 (bersifat basa).

Kandungan $\mathrm{Na}_{2} \mathrm{O}$ dalam Natrium bentonit umumnya lebih besar dari 2\%. Karena sifat-sifat tersebut maka mineral ini sering dipergunakan untuk lumpur pemboran, penyumbat kebocoran bendungan pada Teknik Sipil, bahan pencampur pembuatan cat, bahan baku

farmasi, dan perekat pasir cetak pada industri pengecoran logam. 


\subsubsection{Kalsium Bentonit}

Bentonit jenis ini disebut juga $\mathrm{Mg}, \mathrm{Ca}$-Bentonit. Jenis ini mengandung kalsium $\left(\mathrm{K}_{2} \mathrm{O}\right)$ dan magnesium $(\mathrm{MgO})$ lebih banyak dibandingkan natriumnya, mempunyai sifat sedikit menyerap air sehingga apabila didipersikan dalam air akan cepat mengendap (tidak membentuk suspensi), $\mathrm{pH}$ nya berkisar $4,0-$ 7,0 (bersifat asam). Daya tukar ion (KTK) cukup besar dan bersifat menyerap. Karena sifat-sifat tersebut maka Kalsium Bentonit dipergunakan untuk bahan pemucat warna untuk minyak.

\subsection{Bentonit Kabupaten Tasikmalaya}

Daerah-daerah yang memiliki endapan Bentonit terdiri dari sembilan kecamatan (Gambar 1) meliputi Kecamatan Karangnunggal, Kecamatan Bantar Kalong, Kecamatan Cibalong, Kecamatan Bojongasih, Kecamatan Cikatomas, Kawalu, Taraju dan Sukaraja dan Manonjaya umumnya terdapat pada satuan tufa pada Formasi Bentang dan Formasi Jampang, terbentuk akibat devitrifikasi dan hidrotermal mempunyai sumberdaya sebesar 19.812.600 ton (Parningotan, M.R., 2002)

Bentonit di daerah Taraju terdapat berupa singkapan-singkapan kecil, berwarna abu-abu kekuningan sampai kehijauan, di selingi oleh batupasir dan breksi, sehingga sulit menentukan sebarannya. Hasil analisa BP sebelum diaktifkan 2 rendah sekali setelah diaktifkan 85, nilai KTK 16.92 meq \%. (Yusuf,A.F., dkk., 2004).

Bentonit di daerah Sukaraja luas sebarannyal sekitar $80 \mathrm{Ha}$, dijumpai 2 lokasi, yaitu lokasi Sukapura dan Tarunajaya, ketebalan rata-rata endapan bentonit di kedua wilayah ini $1,5 \mathrm{~m}$, sumberdaya tereka sekitar 1,2 juta $\mathrm{m}^{3}$, berwarna abuabu kekuningan sampai kehijauan. Hasil analisa BP menunjukan harga BP sebelum diaktifkan 34 dan 18 , setelah diaktifkan masing-masing 90 dan 87 , bentonit Cibariluk harga BP sebelum diaktifkan 54 sesudah diaktifkan 91, selain harga BP bentonit Cibariluk mempunyai harga KTK paling tinggi di wilayah ini yaitu sebesar 84.43 meq \%.(Yusuf,A.F., dkk., 2004).

Sedangkan di daerah Karangnunggal bentonit telah diusahakan oleh PD Kerta Pertambangan sejak tahun 70an, umumnya perlu diaktifkan dahulu sebelum digunakan sebagai penjernih minyak kelapa/sawit.

Tabel 1. Dugaan Konsumsi Minyak Goreng Indonesia (dalam 000 ton)

\begin{tabular}{|c|c|c|c|c|c|c|c|c|}
\hline Tahun & Minyak Sawit & $\begin{array}{c}+/- \\
(\%)\end{array}$ & $\begin{array}{c}\text { Kontribusi } \\
(\%)\end{array}$ & $\begin{array}{r}\text { Minyak } \\
\text { Kelapa }\end{array}$ & $\begin{array}{l}+/- \\
(\%)\end{array}$ & \begin{tabular}{|c} 
Kontribusi \\
$(\%)$
\end{tabular} & Total & $\begin{array}{c}+/- \\
(\%)\end{array}$ \\
\hline 1999 & $2,494.1$ & 4.4 & 77.5 & 725.8 & 7.5 & 22.5 & $3,219.9$ & 5.1 \\
\hline 2000 & $2,806.1$ & 12.5 & 78.5 & 769.5 & 6.0 & 21.5 & $3,575.6$ & 11.0 \\
\hline 2001 & $3,137.9$ & 11.8 & 79.6 & 806.5 & 4.8 & 20.4 & $3,944.4$ & 10.3 \\
\hline 2002 & $3,508.1$ & 11.8 & 80.6 & 846.9 & 5.0 & 19.4 & $4,355.0$ & 10.4 \\
\hline 2003 & $3,964.9$ & 13.0 & 81.8 & 879.8 & 3.9 & 18.2 & $4,844.7$ & 11.2 \\
\hline 2004 & $4,527.7$ & 14.2 & 82.9 & 933.4 & 6.1 & 17.1 & $5,461.1$ & 12.7 \\
\hline 2005 & $5,062.8$ & 11.8 & 83.8 & 980.4 & 5.0 & 16.2 & $6,043.3$ & 10.7 \\
\hline & umbuhan & 10.1 & & & 3.3 & & & 8.8 \\
\hline
\end{tabular}

Sumber: BIRO/1999 


\section{PENUTUP}

Untuk mengetahui prospek pemanfaatan bahan galian maka pengkajian atau penilaiannya didasarkan pada beberapa aspek antara lain : kualitas, kuantitas, lokasi dan pemasaran, disamping aspek lainnya. Kajian mengenai prospek pengembangan bahan galian tidak terlalu berbeda dengan dasar penilaian terhadap prospek pemanfaatannya. Namun untuk prospek pengembangan lebih diarahkan pada kemungkinan pengusahaan dalam skala yang relatif lebih besar di masa yang akan datang, dikaitkan dengan pusat-pusat pertumbuhan dan peluang ekspor sejalan dengan permintaan pasar dalam dan luar negeri. Untuk mengetahui prospek pemanfaatan dan pengembangan bahan galian bentonit di Kabupaten Tasikmalaya perlu dilakukan analisa potensi dan kegunaan bahan galian tersebut.

Data potensi endapan bentonit di Kabupaten Tasikmalaya masih terbatas baik dalam hal kualitas maupun kuantitas, data yang ada masih bersifat prospek, perlu dilakukan penelitian lebih lanjut serta perlu pengkajian yang teliti dari segi ekonomi maupun lingkungan.

Diharapkan dari hasil kajian yang lebih detail dapat dihasilkan suatu kesimpulan yang pasti mengenai prospek bentonit di Kabupaten Tasimalaya dan dapat memberikan sumbangan bagi industri minyak goreng Indonesia, khususnya di Pulau Jawa.

\section{DAFTAR PUSTAKA}

Arifin, M \& Adjat S., 1997; Bahan Galian Industri, Pusat Penelitian dan Pengembangan Teknologi Mineral, Bandung, hal. 124-137

Budhi Trisna. T, 1986; Geologi Lembar Tasikmalaya, Jawa Barat, Pusat Penelitian dan Pengembangan Geologi, Bandung

Lepond, S. J., 1975; Industrial Mineral and Rocks, $4^{\text {th }}$ ed., Seeley W., Muud Series, McGraw-Hill Company

Parningotan,M.R., dkk., 2002; Inventarisasi dan Evaluasi Mineral Non Logam di Kab. Ciamis dan Kab. Tasik, Prov. Jawa Barat, DIM, Bandung

Supriatna, S., dkk, 1992; Peta Geologi Lembar Karangnunggal. Pusat Penelitian dan Pengembangan Geologi, Bandung.

Riyanto, A., 1994; Bahan Galian Industri BENTONIT, Dirjen Pertambangan Umum, PPTM, Bandung.

Yusuf,A.F., dkk., 2004, Pemetaan Endapan fosfat di daerah Taraju dan Sukaraja, Kabupaten Tasikmalaya www.bbi.jfx.com/ 2006 Perkembangan Produksi Minyak Goreng Sawit Di Indonesia 